\title{
Interface interaction of transition metal phthalocyanines with strontium titanate (100)
}

\author{
Reimer Karstens ${ }^{1}$, Thomas Chassé ${ }^{1,2}$ and Heiko Peisert ${ }^{*}$
}

\author{
Full Research Paper \\ Address: \\ ${ }^{1}$ Institute of Physical and Theoretical Chemistry, University of \\ Tübingen, Auf der Morgenstelle 18, 72076 Tübingen, Germany and \\ ${ }^{2}$ Center for Light-Matter Interaction, Sensors \& Analytics (LISA+) at \\ the University of Tübingen, Auf der Morgenstelle 18, 72076 Tübingen, \\ Germany \\ Email: \\ Heiko Peisert ${ }^{*}$ - heiko.peisert@uni-tuebingen.de \\ ${ }^{*}$ Corresponding author \\ Keywords: \\ charge transfer at interfaces; strontium titanate; transition metal \\ phthalocyanines \\ Beilstein J. Nanotechnol. 2021, 12, 485-496. \\ https://doi.org/10.3762/bjnano.12.39 \\ Received: 21 January 2021 \\ Accepted: 07 May 2021 \\ Published: 21 May 2021 \\ Associate Editor: E. Meyer \\ (C) 2021 Karstens et al.; licensee Beilstein-Institut. \\ License and terms: see end of document.
}

\begin{abstract}
We study interface properties of $\mathrm{CoPcF}_{x}$ and $\mathrm{FePcF}_{\mathrm{X}}\left(x=0\right.$ or 16) on niobium-doped $\mathrm{SrTiO}_{3}(100)$ surfaces using mainly $\mathrm{X}$-ray photoelectron spectroscopy and ultraviolet photoelectron spectroscopy. For all studied molecules, a rather complex, bidirectional charge transfer with the oxide substrate was observed, involving both the macrocycle and the central metal atom. For molecules of the first monolayer, an electron transfer to the central metal atom is concluded from transition metal $2 p$ core level photoemission spectra. The number of interacting molecules in the first monolayer on the oxide surface depends on the central metal atom of the phthalocyanine, whereas the substrate preparation has minor influence on the interaction between $\mathrm{CoPc}_{\text {and }} \mathrm{SrTiO}_{3}(100)$. Differences of the interaction mechanism to related $\mathrm{TiO}_{2}$ surfaces are discussed.
\end{abstract}

\section{Introduction}

Interfaces between organic semiconductors and oxides are of increasing fundamental interest. Such interfaces determine key properties of a broad variety of electronic devices. Common examples are dye-sensitized solar cells, field-effect transistors (FETs), and sensors [1,2]. Possibly, one of the most extensively studied oxide material in this context is rutile titanium dioxide [3]. However, also interfaces between $\mathrm{SrTiO}_{3}$ (STO) and organic molecules are studied increasingly using both experimental $[4,5]$ and theoretical approaches [6]. Possible applications of STO/organic interfaces include FETs $[7,8]$, photodiodes [9], and organic spin valves[10].

Strontium titanate is a semiconductor with an indirect band gap of $3.25 \mathrm{eV}$ [11] crystallizing in a perovskite structure with cubic 
unit cell. The conductivity can be increased by introducing oxygen vacancies into the crystal structure or by doping (e.g., n-type doping with niobium, $\mathrm{Nb}^{5+}$ ). Generally, two different terminations of $\mathrm{STO}(100)$ are known, that is, the surface can be either $\mathrm{TiO}_{2}$ - or SrO-terminated. The $\mathrm{TiO}_{2}$ termination can be achieved by (ex situ) acid treatments $[12,13]$ or water leaching $[14,15]$. The $\mathrm{SrO}$ termination is often achieved via thermal $\mathrm{Sr}$ segregation [16-18] or by deposition of $\mathrm{SrO}$ in vacuo $[19,20]$. Due to the thermal Sr segregation effect, sputtering and annealing procedures result commonly in SrO-terminated surfaces [21]. The detailed preparation procedures differ distinctly. For example, the temperature range for $\mathrm{Sr}$ segregation reaches from $570 \mathrm{~K}$ [22] to $1570 \mathrm{~K}$ [23]. In many cases, mixed surface terminations are obtained consisting of multiple islands of dominant terminations or SrO droplets [21,22,24,25].

$\mathrm{SrTiO}_{3}(100)$ bulk structures are visualized in Figure 1. LEED measurements (see below) gave no evidence for the appearance of occasionally discussed surface reconstructions after our preparation procedures [26,27]. In Figure $1 \mathrm{a}$ a $\mathrm{TiO}_{2}$-terminated surface is shown, where $\mathrm{Ti}^{4+}$ (light blue) and $\mathrm{O}^{2-}$ (red) ions form the outmost (top) layer. In contrast, the top layer of SrO-terminated STO in Figure $1 \mathrm{~b}$ contains $\mathrm{Sr}^{2+}$ (green) and $\mathrm{O}^{2-}$ (red) ions, only. The length of the cubic lattice vectors is $3.91 \AA$ [28] for both terminations. Due to the same symmetry of the surface structure, unfortunately, we cannot distinguish between different terminations by LEED. It might be expected that the presence of the different metal ions on the substrate surface ( $\mathrm{Sr}$ or $\mathrm{Ti}$ ) affects possible interactions with deposited organic molecules. We note that the surface structure in the topmost layer of $\mathrm{TiO}_{2}$-terminated STO significantly differs from most rutile $\mathrm{TiO}_{2}$ surfaces (e.g., (110) and (100)). In particular due to the presence of both $\mathrm{Ti}^{4+}$ and $\mathrm{O}^{2-}$ ions in the topmost layer of STO we may expect differences regarding molecule-oxide interactions.
The present study investigates interface interactions between different STO(100) surfaces and organic molecules. The general chemical structure of the chosen molecules is shown in Figure 1c. The electronic properties of transition metal phthalocyanines (TMPcs) can be widely chemically modified at both the central metal atom and the macrocycle. This chemical tunability allows for a broad variation of electronic properties. Hence, TMPcs are well suited for systematic studies of interface properties. The fluorination of TMPcs varies exceptionally the ionization potential (IP), affecting distinctly the interface properties [29-32]. As recently shown for $\mathrm{FePcF}_{x} / \mathrm{MoS}_{2}$ [33], a charge transfer at interfaces might be driven by the ionization potential difference between substrate and adsorbate. In addition, fluorination may affect significantly the adsorption geometry on surfaces as well as the single-crystal structure and arrangement in thin films [34-37]. Furthermore, local chemical interactions might become possible between particular atoms of substrate and adsorbate. For example, for many CoPc and $\mathrm{CoPcF}_{16}$ interfaces to noble metals, the interfacial interaction is governed by a local interaction between the Co $3 \mathrm{~d}_{z 2}$ orbital and states of the metal substrate [38-40]. Thus, the selected TMPcs allow for the study of both the influence of the ionization potential and the central metal atom on the properties of interfaces with differently prepared STO surfaces.

\section{Experimental}

Niobium-doped strontium titanate (100) (Nb:STO) single crystals were purchased from MaTeck $\mathrm{GmbH}$ (Jülich, Germany; $10 \times 10 \times 0.5 \mathrm{~mm}^{3}, 0.5 \mathrm{wt} \% \mathrm{Nb}$ ). The surfaces were typically prepared in vacuo by repeated cycles of Ar ion sputtering $\left(0.5 \mathrm{kV}, p(\mathrm{Ar})=5 \times 10^{-5} \mathrm{mbar}, 30 \mathrm{~min}\right)$ and annealing $(900 \mathrm{~K}$, $\left.p\left(\mathrm{O}_{2}\right)=4 \times 10^{-5} \mathrm{mbar}, 30 \mathrm{~min}\right)$. This method is called "preparation I" in the following. We note that this procedure results in a predominantly SrO-terminated, but mixed crystal surface. In order to modify the surface preparation, another procedure, a)

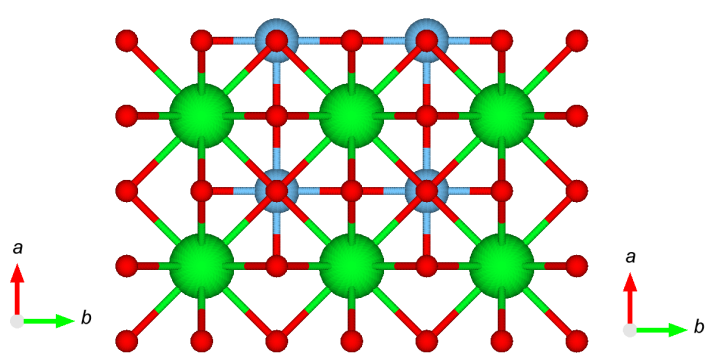

b)

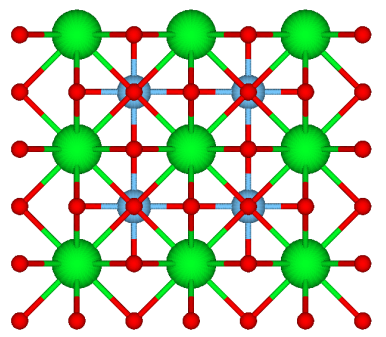

c)

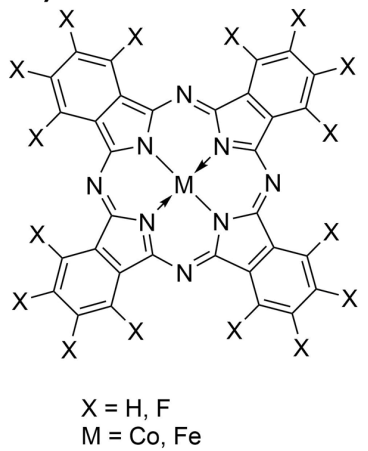

Figure 1: Bulk crystal structures (side views) of: (a) $\mathrm{TiO}_{2}$-terminated strontium titanate (100) and (b) SrO-terminated strontium titanate (100) ( $\mathrm{Ti}^{4+}$ light blue, $\mathrm{Sr}^{2+}$ : green, and $\mathrm{O}^{2-}$ : red. The coordinate axes $a, b$, and $c$ correspond, respectively, to the crystal orientations (100), (010), and (001)). (c) General chemical structure of transition metal phthalocyanines (TMPcs). 
called "preparation II", was applied. After a wet chemical preparation, a monolayer of $\mathrm{TiO}_{2}$ was grown epitaxially on top of the STO surface by evaporation of Ti $(0.6 \AA)$ in an oxygen atmosphere $\left(p\left(\mathrm{O}_{2}\right)=4 \times 10^{-5} \mathrm{mbar}\right)$ at a substrate temperature of $910 \mathrm{~K}$. The Ti thickness was monitored by the ion flux of the electron beam evaporator (EFM 3s, Focus GmbH) calibrated by a quartz microbalance. The estimation of the $\mathrm{TiO}_{2}$ thickness from the attenuation of the $\mathrm{Sr} 3 \mathrm{~d}$ peak intensity supports the presence of an additional $\mathrm{TiO}_{2}$ layer on the STO substrate.

FePc (dye content 90\%), $\mathrm{CoPc}$ and $\mathrm{CoPcF}_{16}$ were purchased from Sigma Aldrich Chemie GmbH (Steinheim, Germany), and $\mathrm{FePcF}_{16}$ was purchased from Synthon Chemicals $\mathrm{GmbH} \& \mathrm{Co}$. $\mathrm{KG}$ (Bitterfeld-Wolfen, Germany). FePc and $\mathrm{FePcF}_{16}$ powders were resublimed before usage. The materials were evaporated from temperature-controlled crucibles. The nominal layer thickness was estimated from substrate- and adsorbate-related XPS intensity ratios using photoemission cross sections from Yeh and Lindau [41]. A nominal monolayer of lying molecules corresponds to a thickness of $0.34 \mathrm{~nm}$ estimated from the structure of an $\alpha$-polymorph of TMPcs [42-44].

Photoelectron spectroscopy (PES) measurements were performed using an ultrahigh-vacuum setup equipped with a monochromatized standard source ( $\mathrm{Al} \mathrm{K} \alpha$ ), a twin-anode standard source ( $\mathrm{Al} \mathrm{K} \alpha$ and $\mathrm{Mg} \mathrm{K} \alpha$ ), PHOIBOS 100 (X-ray photoelectron diffraction) or 150 (monochromatized X-ray photoelectron spectroscopy) hemispherical analyzers (SPECS), and a fourgrid LEED optics (SpectaLEED, Omicron, Germany). The PES binding energy scale is calibrated to reproduce the binding energies of $\mathrm{Cu} 2 \mathrm{p}_{3 / 2}(932.6 \mathrm{eV}), \mathrm{Ag} \mathrm{3} \mathrm{d}_{5 / 2}(368.2 \mathrm{eV})$, and $\mathrm{Au} 4 \mathrm{f}_{7 / 2}$ $(84.0 \mathrm{eV})$. For X-ray photoelectron diffraction measurements, the angular acceptance of the analyzer was set to $\pm 4^{\circ}$. Angular distribution curves were measured for the $\mathrm{Sr} 3 \mathrm{~d}$, Ti $2 \mathrm{p}$, and $\mathrm{O} 1 \mathrm{~s}$ photoemission peaks at two azimuths ([100] and [110], determined by LEED); the step width of the polar angle was $2^{\circ}$. The peak intensity was normalized by dividing the peak maximum by the background mean value at the lower binding energy side. PES spectra were analyzed using UNIFIT 2018 [45]. For the illustration of crystal structures the software VESTA [46] was used.

\section{Results and Discussion \\ Characterization of the substrate surfaces}

For related interfaces between rutile $\mathrm{TiO}_{2}$ and organic molecules, significantly different interaction strengths in similar systems were reported, which can be most likely ascribed to different substrate preparation procedures [47-50]. Therefore, we will apply two different, well-characterized preparation procedures. For preparation I, the STO single crystal was cleaned in vacuo as described above. Routinely, the cleanliness is checked by X-ray photoelectron spectroscopy and the quality of the surface structure by LEED. Examples of LEED images are shown in Supporting Information File 1 (Figure S1). It was reported that the work function $\phi_{\mathrm{F}}$ correlates strongly with the termination of the STO substrate surface [19]. For SrO-terminated $\mathrm{STO}(100) \phi_{\mathrm{F}}$ is significantly lower $(3.1-3.6 \mathrm{eV})$ than for $\mathrm{TiO}_{2-}$ terminated STO(100) $(4.5-4.8 \mathrm{eV})$. The work function, as determined from photoemission, was close to $3.9 \mathrm{eV}$ for all STO single crystals prepared according to preparation I, indicating a mixed surface termination, likely with a slightly dominant contribution of SrO. In contrast, for preparation II, we obtained work functions between $3.93 \mathrm{eV}$ (preparation II, experiment 2) and $4.15 \mathrm{eV}$ (preparation II, experiment 1), although a very similar annealing procedure was applied. The work function variations indicate that different fractions of mixed terminations were prepared. The highest value of $4.15 \mathrm{eV}$ points to a predominantly $\mathrm{TiO}_{2}$-terminated $\mathrm{STO}(100)$ surface. We assume that the final work function depends critically on the diffusion of $\mathrm{Sr}$ ions during the final annealing step and thus slightly different evaporation conditions or sample temperatures influence the surface composition distinctly. The different termination for samples with different work function is supported by the $\mathrm{Ti} / \mathrm{Sr} / \mathrm{O}$ ratios determined from overview spectra: We obtain $\mathrm{Ti} / \mathrm{Sr} / \mathrm{O}=1: 1.28: 2.61$ for the sample with $\phi_{\mathrm{F}}=4.15 \mathrm{eV}$ and $\mathrm{Ti} / \mathrm{Sr} / \mathrm{O}=1: 1.45: 2.80$ for the sample with $\phi_{\mathrm{F}}=3.93 \mathrm{eV}$. Typical values for samples prepared according to preparation I are $\mathrm{Ti} / \mathrm{Sr} / \mathrm{O}=1: 1.46: 2.85$. We note that these values should be compared only relatively; absolute numbers are strongly influenced by photoelectron diffraction effects (see next paragraph).

Another method to analyze the termination of the STO(100) surface is X-ray photoelectron diffraction [26,51]. We measured angular distribution curves (ADCs) for $\mathrm{Sr} 3 \mathrm{~d}$, Ti $2 \mathrm{p}$, and $\mathrm{O} 1 \mathrm{~s}$ at two azimuths ([100] and [110]) with a variation of the polar angle between normal emission $\left(0^{\circ}\right)$ and $30^{\circ}$ with a step width of $2^{\circ}$. Comparably sensitive to the surface termination are ADCs of the Sr 3d peak at the [100] azimuth [51,52]; examples are shown in Figure S2, Supporting Information File 1. While the different shape may generally indicate the presence of different surface structures, here, we obtain no unambiguous information about the actual surface termination, most likely due to the rather mixed termination already mentioned above. However, we can confirm the structural ordering of the near-surface region below the topmost layer, and we may rule out a completely SrO-terminated surface.

\section{$\mathrm{CoPcF}_{X}$ on STO(100)}

Possible interactions between organic molecules and different substrates may include charge transfer processes or even chemical reactions. In the case of semiconducting substrates, such a 
charge transfer would result in an interface doping of the substrate. Depending on the charge carrier concentration, the doping is accompanied by a shift of the Fermi level, visible as rigid energy shifts of all substrate-related core level spectra in photoemission.

As an example, we discuss the development of Ti $2 p$ spectra with increasing thickness of the organic overlayer $(\mathrm{CoPc}$ or $\left.\mathrm{CoPcF}_{16}\right)$ in Figure 2, $\mathrm{Sr} 3 \mathrm{~d}$ and $\mathrm{O}$ 1s spectra are shown in Figure S3 and Figure S4 (Supporting Information File 1). All peak fit parameters are supplied in Supporting Information File 1 (Tables S1-S6).

All Ti 2 p spectra in Figure 2 can be described by a single doublet arising from spin-orbit splitting, which can be assigned to $\mathrm{Ti}^{4+}$ ions of the substrate. The binding energy of the Ti $2 \mathrm{p}_{3 / 2}$ component of the pristine substrate is $459.15 \mathrm{eV}$ (Figure 2a) or $458.9 \mathrm{eV}$ (Figure $2 \mathrm{~b}$ ), indicating a slightly different position of the Fermi level in the gap of the STO semiconductor. Upon evaporation of the organic molecules, no changes of the peak shape can be detected, pointing to the absence of chemical interactions involving $\mathrm{Ti}$ atoms at the interface. However, we note that the surface sensitivity at the comparably high kinetic energies (mean free path of electrons about $2 \mathrm{~nm}$ ) may hinder the unambiguous detection of different chemical states in the uppermost layer. Analogously, also for the other substrate- related $\mathrm{O}$ 1s and $\mathrm{Sr} 3 \mathrm{~d}$ spectra (Figure S2 and Figure S3, Supporting Information File 1), no interface components were found. The small shift of the Ti $2 p$ spectra in Figure 2a after deposition of CoPc to lower binding energies is also observed in the corresponding $\mathrm{O} 1 \mathrm{~s}$ and $\mathrm{Sr} 3 \mathrm{~d}$ spectra (Figure S2 and Figure S3, Supporting Information File 1) and might be assigned to an adsorbate-induced band bending at the interface (p-type doping).

Adsorbate-related core level spectra are shown in Figure 3 for different film thicknesses. For the $0.25 \mathrm{~nm}$ and the $0.45 \mathrm{~nm}$ film, the $\mathrm{Sr} 3 \mathrm{p}_{1 / 2}$ background was subtracted in the $\mathrm{C} 1 \mathrm{~s}$ spectra. Original data and the background procedure are shown in Figure S5 (Supporting Information File 1). The peak fit parameters are given in Table S7 and Table S8 (Supporting Information File 1).

For the thickest films in Figure $3(6.9 \mathrm{~nm})$ the molecule-related core level spectra can be described analogously to the literature of transition metal phthalocyanines [53-55]. A single main component was assumed for $\mathrm{N} 1 \mathrm{~s}$, due to the typically small energy separation of the two chemically inequivalent nitrogen atoms $(0.3 \mathrm{eV}$ for $\mathrm{FePc}$ [56]). For $\mathrm{C} 1 \mathrm{~s}$, we distinguish between aromatic carbon atoms of the benzene rings $(\mathrm{C}-1)$ and pyrrole carbon atoms linked to nitrogen (C-2). All main components in the $\mathrm{N} 1 \mathrm{~s}$ and $\mathrm{C} 1 \mathrm{~s}$ spectra are accompanied by satellite components
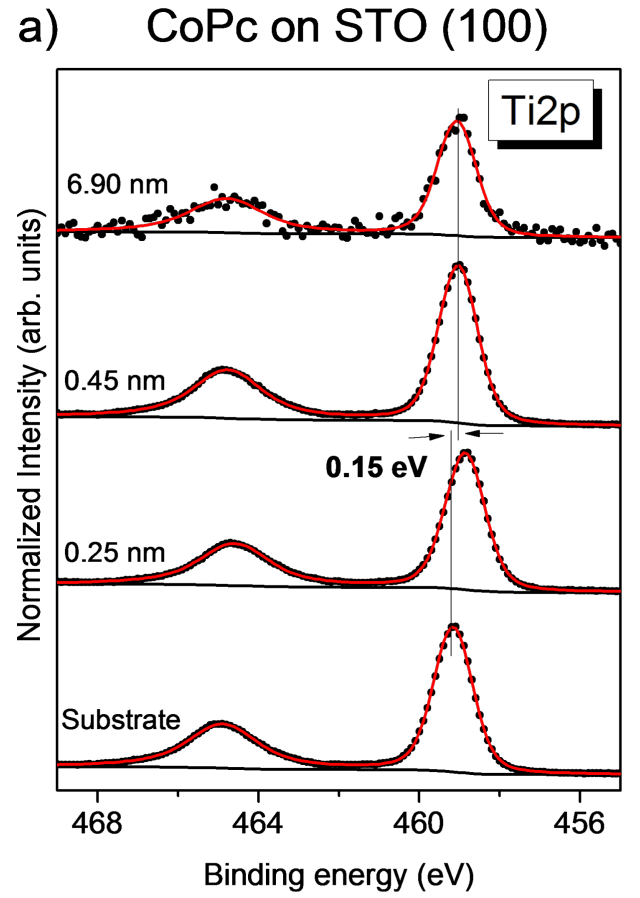

b) $\mathrm{CoPcF}_{16}$ on $\mathrm{STO}(100)$

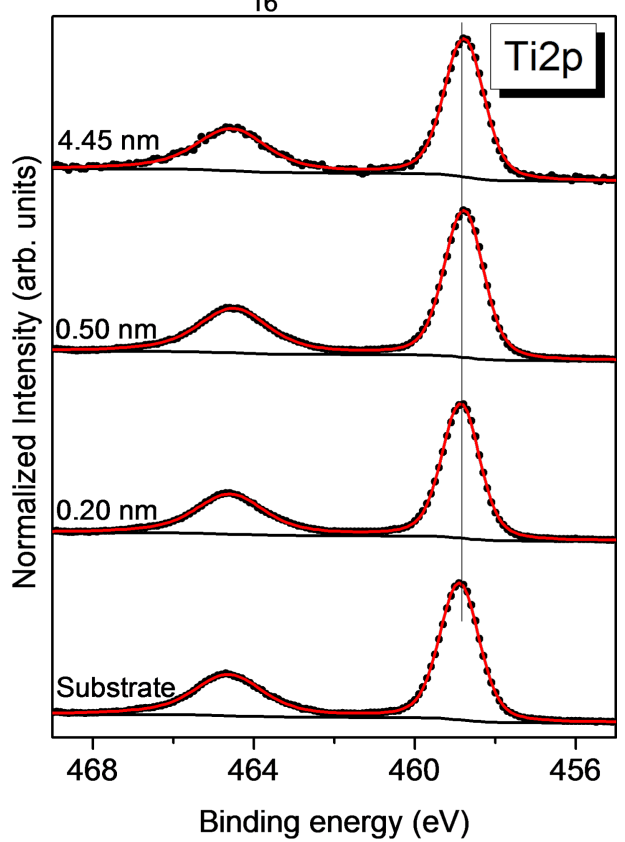

Figure 2: Development of Ti $2 p$ spectra as an example for the change of substrate-related core level spectra with increasing thickness of (a) the CoPc or (b) the $\mathrm{CoPcF}_{16}$ films. 
a) CoPc on $\mathrm{STO}(100)$

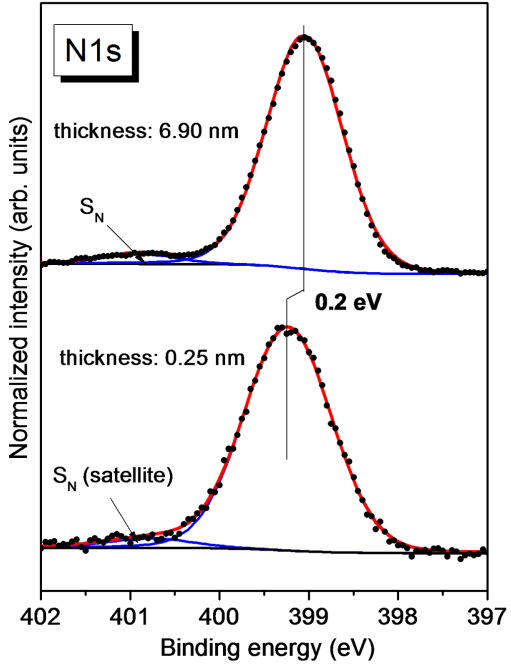

b) CoPc on $\mathrm{STO}(100)$

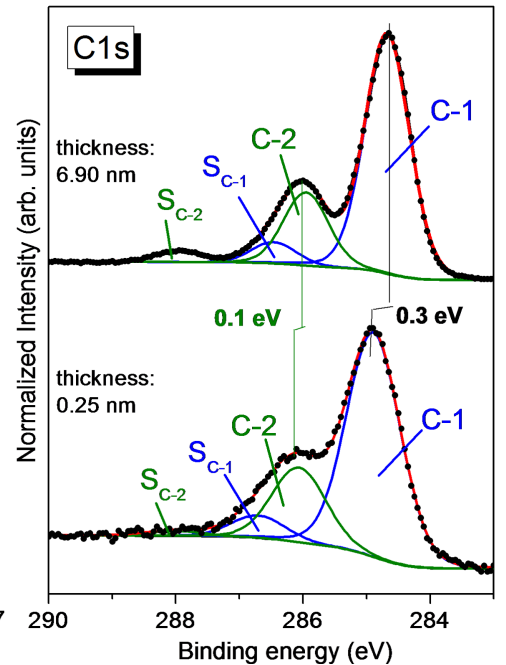

c) CoPc on $\mathrm{STO}(100)$

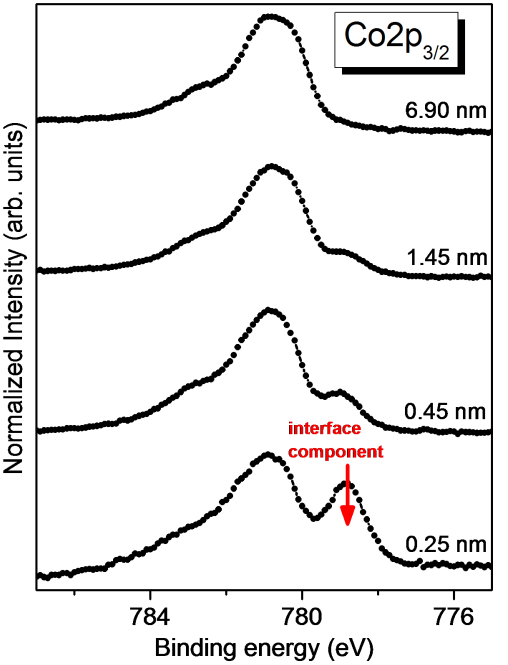

Figure 3: CoPc on STO(100). (a) N 1s, (b) C 1s, and (c) Co 2p core level spectra for a multilayer film compared to a coverage of a monolayer. The Co $2 p$ spectra show clearly an interface component at lower binding energy than the main component (see arrow).

at $1.6-1.8 \mathrm{eV}$ higher binding energy $\left(\mathrm{S}_{\mathrm{N}}, \mathrm{S}_{\mathrm{C}-1}\right.$, and $\left.\mathrm{S}_{\mathrm{C}-2}\right)$. The shape of the Co $2 p_{3 / 2}$ spectrum is characterized by complex multiplet structures of the $\mathrm{Co}(\mathrm{II})$ ion with $\mathrm{d}^{7}$ electron configuration $[39,55,57,58]$.

The monolayer spectra $(0.25 \mathrm{~nm})$ of the macrocycle $(\mathrm{N} 1 \mathrm{~s}$ and $\mathrm{C} 1 \mathrm{~s}$ ) in Figure 3 can be essentially described by the model applied for the bulk-like thicker films. For both $\mathrm{N} 1 \mathrm{~s}$ and $\mathrm{C} 1 \mathrm{~s}$ spectra, a slight broadening is observed for monolayer spectra compared to the bulk. The Gaussian width increases from 1.0 to $1.1 \mathrm{eV}$ and from 0.8 to $0.9 \mathrm{eV}$ for $\mathrm{N} 1 \mathrm{~s}$ and $\mathrm{C} 1 \mathrm{~s}$, respectively. Such a broadening might be ascribed to adsorption at inequivalent adsorption sites or other kinds of disorder, which may result in a statistical distribution of orbital energies [59]. Also visible is a shift of the monolayer $\mathrm{N} 1 \mathrm{~s}$ and $\mathrm{C} 1 \mathrm{~s}$ core level spectra to $0.2-0.3 \mathrm{eV}$ higher binding energies with respect to the $6.9 \mathrm{~nm}$ film in Figure 3. Many reasons, including charge transfer and a different screening of the photohole due to a different environment, may cause such shifts. The shift to higher binding energy at the substrate interface is rather unlikely for screening and might therefore point to a charge transfer from the macrocycle of the molecule to the substrate. This does generally not contradict the abovementioned p-type doping of the substrate surface, which is connected to the total interface charge redistribution, because our data indicate also a substantial opposite charge transfer towards the Co central metal atoms of the molecules in the first monolayer (see below). The different shifts for $\mathrm{N} 1 \mathrm{~s}$ and $\mathrm{C} 1 \mathrm{~s}$ components point to a different charge distribution for the monolayer compared to the thick film, in good agreement to $\mathrm{CoPcF}_{16}$ on STO discussed below.
Most visible are thickness-dependent changes of the shape of Co $2 p_{3 / 2}$ spectra in Figure $3 \mathrm{c}$. At the low binding energy side of the main structure at about $780.9 \mathrm{eV}$, a new peak develops with decreasing film thickness. The binding energy difference of about $2 \mathrm{eV}$ reminds of interface interactions observed at both metallic and oxidic substrates [39,40,58,60-62]. The lower binding energy of the interface component arises from an electron transfer to the central Co ion of CoPc, which can be accompanied by a backdonation from the macrocycle to the substrate $[61,62]$, in good agreement to the observed binding energy shifts of $\mathrm{N} 1 \mathrm{~s}$ and $\mathrm{C} 1 \mathrm{~s}$ core level spectra discussed above. The remaining intensity of the main component at the lowest coverage of $0.25 \mathrm{~nm}$ in Figure 3c indicates that not all molecules of the first layer are involved in the interaction. In other words, the strength of the interface interaction depends on the particular adsorption site.

The question arises whether or not the interaction is further affected by the fluorination of the CoPc molecule. C 1s, F 1 s and $\mathrm{Co} 2 \mathrm{p}_{3 / 2}$ core level spectra of $\mathrm{CoPcF}_{16}$ on STO are shown in Figure 4. The peak fit data are given in Table S9 and Table S10 (Supporting Information File 1). The corresponding N 1s core level spectra are similar to those of $\mathrm{CoPc}$; they are also shown in Figure S6 (Supporting Information File 1). Analogously to $\mathrm{CoPc}$, the core level spectra can be well described using models from the literature. As for $\mathrm{CuPcF}_{16}$ [29], in the $\mathrm{C}$ 1s core level spectra, besides the components $\mathrm{C}-1$ and $\mathrm{C}-2$ in the $\mathrm{CoPc} \mathrm{C} 1 \mathrm{~s}$ spectra, an additional component (C-3) accompanied by a satellite peak has to be introduced. The peak fit of the bulk-like, thickest film reproduces well the stoichiometric com- 

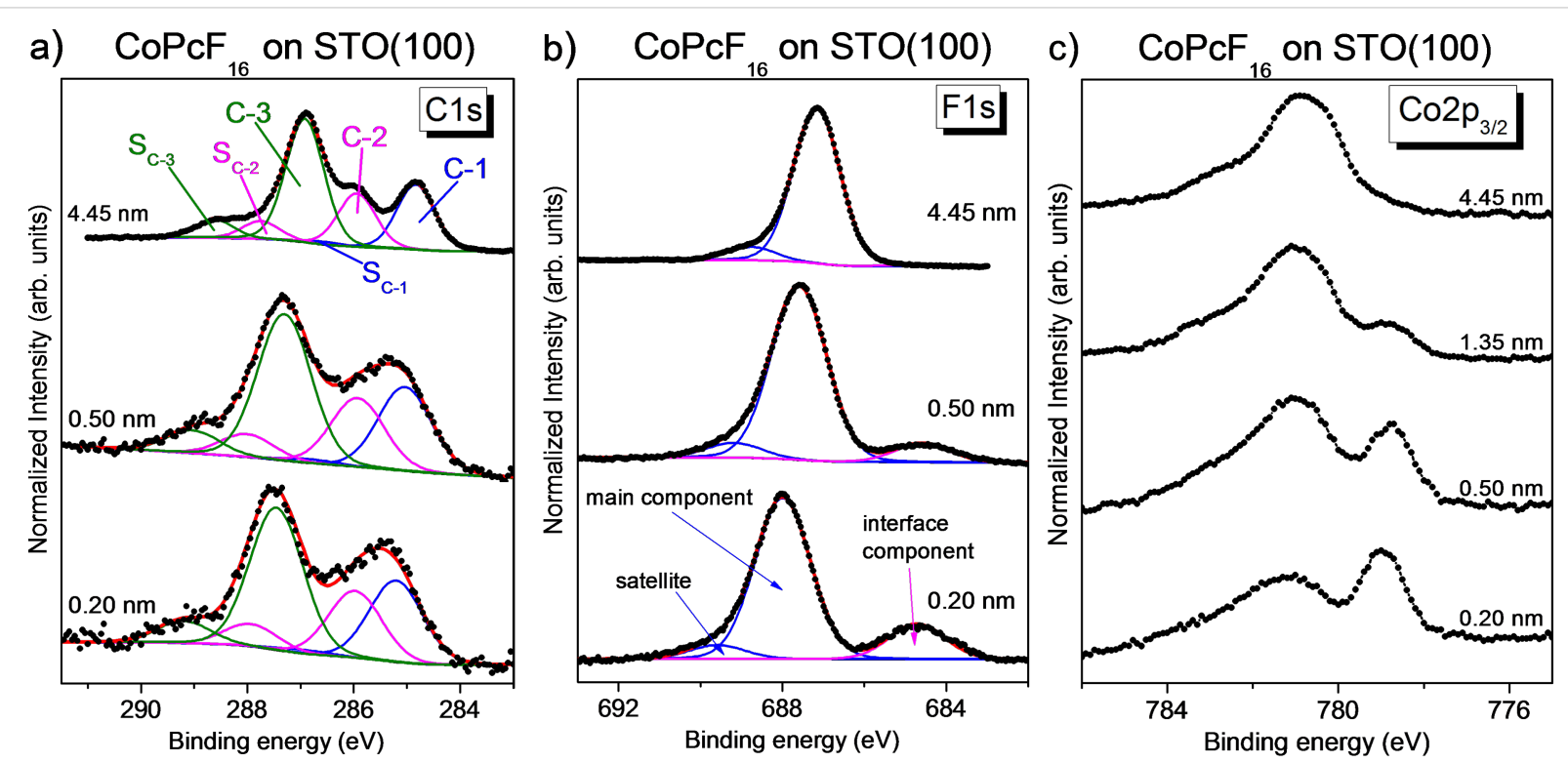

Figure 4: $\mathrm{CoPcF}_{16}$ on $\mathrm{STO}(100)$. Thickness-dependent core level spectra: (a) C 1s, (b) F 1s, and (c) Co $2 \mathrm{p}_{3 / 2}$. Distinct interface components are visible in the $\mathrm{F} 1 \mathrm{~s}$ and $\mathrm{Co} 2 \mathrm{p}_{3 / 2}$ spectra.

position (see Tables S9-S11, Supporting Information File 1). Single components and a satellite were used for fitting the $\mathrm{N} 1 \mathrm{~s}$ and $F$ 1s spectra. The multiplet structure of the Co $2 \mathrm{p}_{3 / 2}$ spectrum is similar to that of $\mathrm{CoPc}$ (Figure 3).

Similar to the case of CoPc, core level spectra related to the macrocycle are broadened at low coverages, possibly due to different adsorption sites on the substrate lattice. Also, distinct shifts to higher binding energies can be detected with decreasing film thickness. Trends for binding energy shifts of the C-1 component as a function of the $\mathrm{CoPc}$ (and $\mathrm{FePc}$ ) thickness are almost independent on the substrate preparation, as summarized in Figure S7 (Supporting Information File 1). A closer look at the peak positions summarized in Table 1 reveals that the shifts are not the same for each component; they range from 0.1 to $0.8 \mathrm{eV}$. The different peak shifts indicate a different charge distribution for molecules of the first monolayer and thus point to a rather complex, bidirectional charge transfer involving the macrocycle of $\mathrm{CoPcF}_{16}$

Table 1: Binding energy shifts of core level spectra of $\mathrm{CoPcF}_{16}$ as a function of the film thickness.

\begin{tabular}{llllll} 
& C-1 & C-2 & C-3 & N 1s & F 1s \\
\hline $4.45 \mathrm{~nm}$ & 284.8 & 285.9 & 288.9 & 398.9 & 687.2 \\
$0.2 \mathrm{~nm}$ & 285.2 & 286.0 & 289.3 & 399.4 & 688.0 \\
$\Delta E$ & 0.4 & 0.1 & 0.4 & 0.5 & 0.8
\end{tabular}

In addition, a distinct interface component is visible in the $\mathrm{F} 1 \mathrm{~s}$ spectra of Figure $4 \mathrm{~b}$ at low coverages. The low binding energy of $684.7 \mathrm{eV}$ points to the formation of metal-fluorine bonds (e.g., Ti-F) $[63,64]$. Thus, we assume that some of the $\mathrm{C}-\mathrm{F}$ bonds of the $\mathrm{CoPcF}_{16}$ molecules are broken at the interface, most likely at more reactive sites only. This is qualitatively in good agreement with the smaller relative intensity of the $\mathrm{C}-\mathrm{F}$ bonding related to the $\mathrm{C}-3$ component in the corresponding $\mathrm{C} 1 \mathrm{~s}$ spectra at the interface (cf. Table S9, Supporting Information File 1). From the $\mathrm{F} 1 \mathrm{~s}$ peak fit we conclude an average of two to three broken C-F bonds per molecule (Table S10, Supporting Information File 1). We note that on defect-rich, highly reactive $\mathrm{TiO}_{2}(100)$ a similar effect has been observed [50]. It might be expected that the breaking of $\mathrm{C}-\mathrm{F}$ bonds will significantly affect electronic interface properties. The bond breaking might be supported by the higher electronegativity difference between $\mathrm{Ti}$ or $\mathrm{Sr}$ and fluorine compared to $\mathrm{C}-\mathrm{F}$ and the typically high $\mathrm{Ti}-\mathrm{F}$ and $\mathrm{Sr}-\mathrm{F}$ bond energies. Indeed, a substrate-induced decomposition of the $\mathrm{C}-\mathrm{F}$ bond was observed for perfluoropentacene on coinage metals [65]

Another interface component is found in the Co $2 \mathrm{p}_{3 / 2}$ spectra of Figure 4. Similar to CoPc on STO, the interface component appears at about $2 \mathrm{eV}$ lower binding energy $(779.0 \mathrm{eV})$ compared to the main component of the thickest film $(780.9 \mathrm{eV})$. Thus, analogously to CoPc, the interface component in the Co $2 \mathrm{p}_{3 / 2}$ spectra can be understood by an electron transfer from the substrate to the Co ion of $\mathrm{CoPcF}_{16}$. The reduction of the Co ion results in a significant change of the multiplet structure arising from final-state effects due to the overlap of Co $2 p$ and Co $3 d$ 
wave functions. The shape of satellite structures above $780 \mathrm{eV}$ for the reduced Co ion in CoPc is discussed for the $\mathrm{CoPc} / \mathrm{Ag}$ interface in [58]. Since satellite features in Figure 4c appear in the same energy range as the main features of the bulk-related spectrum, an exact determination of the relative amount of reduced Co atoms is difficult; we estimate $60-80 \%$. In addition, this hinders a discussion of thickness-dependent energy shifts of the Co $2 p$ spectra.

Since such a charge transfer is not observed for $\mathrm{CoPc}$ on oxygen-terminated $\mathrm{TiO}_{2}$ surfaces $[49,60]$, one might argue that a local interaction occurs between the metal atoms of the STO terminal layer and the $\mathrm{Co}$ ions of $\mathrm{CoPc}$ or $\mathrm{CoPcF}_{16}$. The different intensity of the interface component in the Co $2 \mathrm{p}_{3 / 2}$ spectra for both molecules may indicate a different arrangement of the molecules on the $\operatorname{STO}(100)$ surface due to the different size of the molecules and/or different intermolecular interactions. A strong repulsion is expected for $\mathrm{CoPcF}_{16}$ with its negatively charged outer fluorine atoms. Further, for $\mathrm{CoPcF}_{16}$, adsorption sites might be triggered by the observed $\mathrm{C}-\mathrm{F}$ bond dissociation. However, uncertainties in the estimation of the monolayer thickness from XPS intensities only cannot be ruled out completely.

\section{FePcF $_{x}$ on STO(100)}

To investigate whether the observed local interaction between the central metal atom of $\operatorname{CoPcF}_{x}(x=0$ or 16) and the STO substrate is specific for the Co ion, we study interface properties of the related system $\mathrm{FePcF}_{x}$ on $\mathrm{STO}(100)$. Similar to $\mathrm{CoPcF}_{x}$ on $\mathrm{STO}(100)$, the substrate-related core level spectra
(Supporting Information File 1, Figure S8 and Figure S9) do not show changes of the peak shape upon FePc deposition, that is, they are not sensitive enough to reveal possible interactions of the topmost layer. Only for $\mathrm{FePcF}_{16}$ on STO (Supporting Information File 1, Figure S9), energy shifts towards $0.2-0.3 \mathrm{eV}$ lower binding energies upon $\mathrm{FePcF}_{16}$ deposition can be detected, which may indicate an adsorbate-induced band bending ( $\mathrm{p}$-type doping, electron transfer from STO to $\left.\mathrm{FePcF}_{16}\right)$.

The macrocycle-related $\mathrm{N} 1 \mathrm{~s}$ and $\mathrm{C}$ 1s core level spectra of FePc (Figure 5a,b) exhibit a thickness dependence, very similar to that for CoPc (cf. Figure 3). A broadening of monolayer spectra is observed, which can be explained by different environments or adsorption sites on the substrate. In addition, different energy shifts for each component are visible, most likely due to a different charge distribution for molecules of the first monolayer compared to the bulk-like, thicker film.

The FePc spectrum of the thicker film in Figure 5c exhibits the typical multiplet structure known for $\mathrm{Fe}^{2+}$ in $\mathrm{FePc}[56,66,67]$ with the intensity maximum at a binding energy of $708.8 \mathrm{eV}$. With decreasing layer thickness, a shoulder at the low binding energy side develops, which can be assigned to an interface peak (red arrow in Figure 5c). The lower binding energy compared to the main component indicates an electron transfer from the substrate to the Fe ion of FePc. For the lowest thickness of $0.25 \mathrm{~nm}$ (less than one monolayer), the interface component at a binding energy of $707.7 \mathrm{eV}$ is not dominant in the spectrum; most intensity is found in the range of bulk-related main struc- a) $\mathrm{FePc}$ on $\mathrm{STO}(100)$

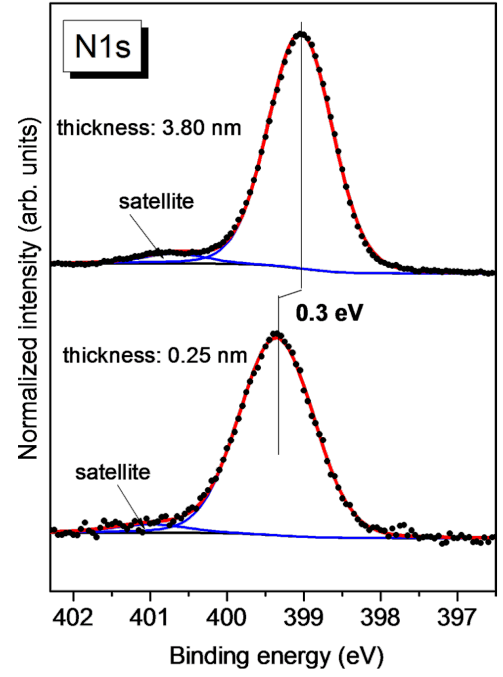

b) $\mathrm{FePc}$ on $\mathrm{STO}(100)$

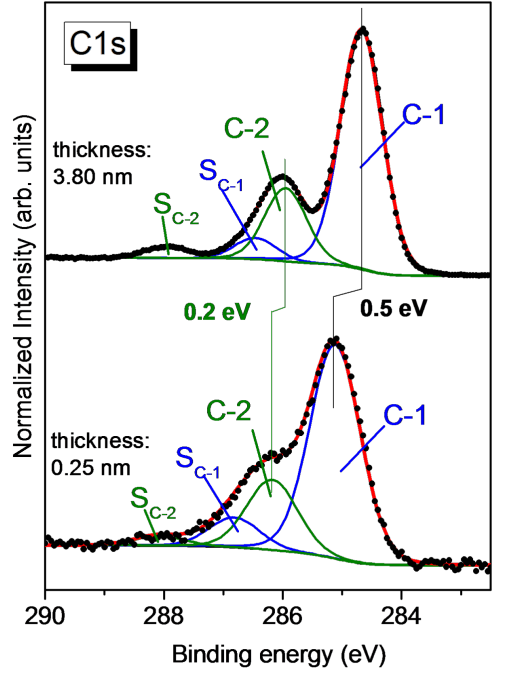

c) $\mathrm{FePc}$ on $\mathrm{STO}(100)$

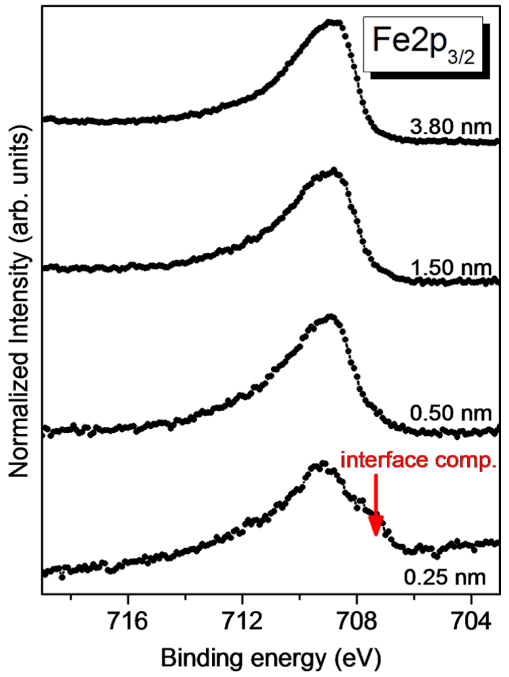

Figure 5: FePc on STO(100). (a) N 1s, (b) C 1s, and (c) Fe 2p core level spectra of multilayer films compared to a coverage of about a monolayer. The Fe $2 p$ spectra show clearly an interface component at the lower binding energy side of the main peak (see arrow). 
tures (shifted to $0.4 \mathrm{eV}$ higher binding energy compared to the bulk). This reveals that not all FePc molecules interact with the STO substrate in the same manner. The estimation of the ratio between interacting/non-interacting molecules is hindered due to lack of a (reference) multiplet spectrum of reduced $\mathrm{Fe}$ ions in FePc. However, comparing Figure $3 \mathrm{c}$ and Figure $5 \mathrm{c}$, it seems to be evident that the number of interacting FePc molecules is smaller than the number of interacting CoPc molecules on STO. This may point to a different adsorption geometry, where the number of molecules adsorbed with the central metal atom at a reactive substrate site is different and the probability is higher in the case of CoPc. A clear template effect of anisotropic substrates is also observed for related strong interacting interfaces [68]. Alternatively, one might speculate that the $\mathrm{Co}$ ion of $\mathrm{CoPc}$ is able to interact also with less reactive sites.

Also for $\mathrm{FePcF}_{16}$, evidence for interactions with the $\mathrm{STO}(100)$ substrate can be detected in the adsorbate-related core level spectra. C 1s and N 1s spectra (Figure S10, Supporting Information File 1) as well as F 1s spectra (Figure 6a) show (different) shifts to higher binding energies for the monolayer, most likely due to charge transfer from the macrocycle to the substrate. Since the interface component in the $\mathrm{Fe} 2 \mathrm{p}_{3 / 2}$ spectra (Figure 6b) and also the substrate-related core level shifts (Figure S9, Supporting Information File 1) point to an opposite electron transfer, the interactions are rather complex and bidirectional.
Considering $\mathrm{CoPcF}_{16}$ on STO (cf. Figure 4b), the F 1s spectrum of the monolayer in Figure 6a exhibits an additional interface component. However, the intensity of the interface peak is distinctly smaller ( $8 \%$ of the main peak, corresponding to one to two broken $\mathrm{C}-\mathrm{F}$ bonds per molecule) compared to $\mathrm{CoPcF}_{16}$. This might point to a different adsorption geometry for both molecules, where the probability of the location of $\mathrm{C}-\mathrm{F}$ bonds at reactive substrate sites is different. The intensity of the interface component in the Fe $2 p_{3 / 2}$ spectra in Figure $6 \mathrm{c}$ is comparable to that of FePc on STO. This indicates that for a comparable number of molecules of the first layer the central $\mathrm{Fe}$ ion interacts with the substrate surface. We note that the shape of the Fe $2 p_{3 / 2}$ spectrum of the thick $\mathrm{FePcF}_{16}$ film in Figure $6 \mathrm{~b}$ is not exactly comparable to the spectrum of the thickest FePc film in Figure 5c, which might be due to a superposition with intense high-energy-loss structures from $\mathrm{F}$ 1s photoemission (at about $688 \mathrm{eV}$ ) or a possible different spin state of Fe in both molecules [69].

In summary, there are no general differences in the interface properties of $\mathrm{FePc}$ and $\mathrm{FePcF}_{16}$ on $\mathrm{STO}(100)$. In both cases, for a significant number of molecules in the first monolayer, an electron transfer to the central Fe ion occurs, whereas an opposite charge transfer is proposed for the macrocycle. In addition, the interface interaction does not solely depend on the transition metal center, there are many similarities for $\mathrm{CoPc} / \mathrm{FePc}$ and $\mathrm{CoPcF}_{16} / \mathrm{FePcF}_{16}$ on $\mathrm{STO}(100)$.
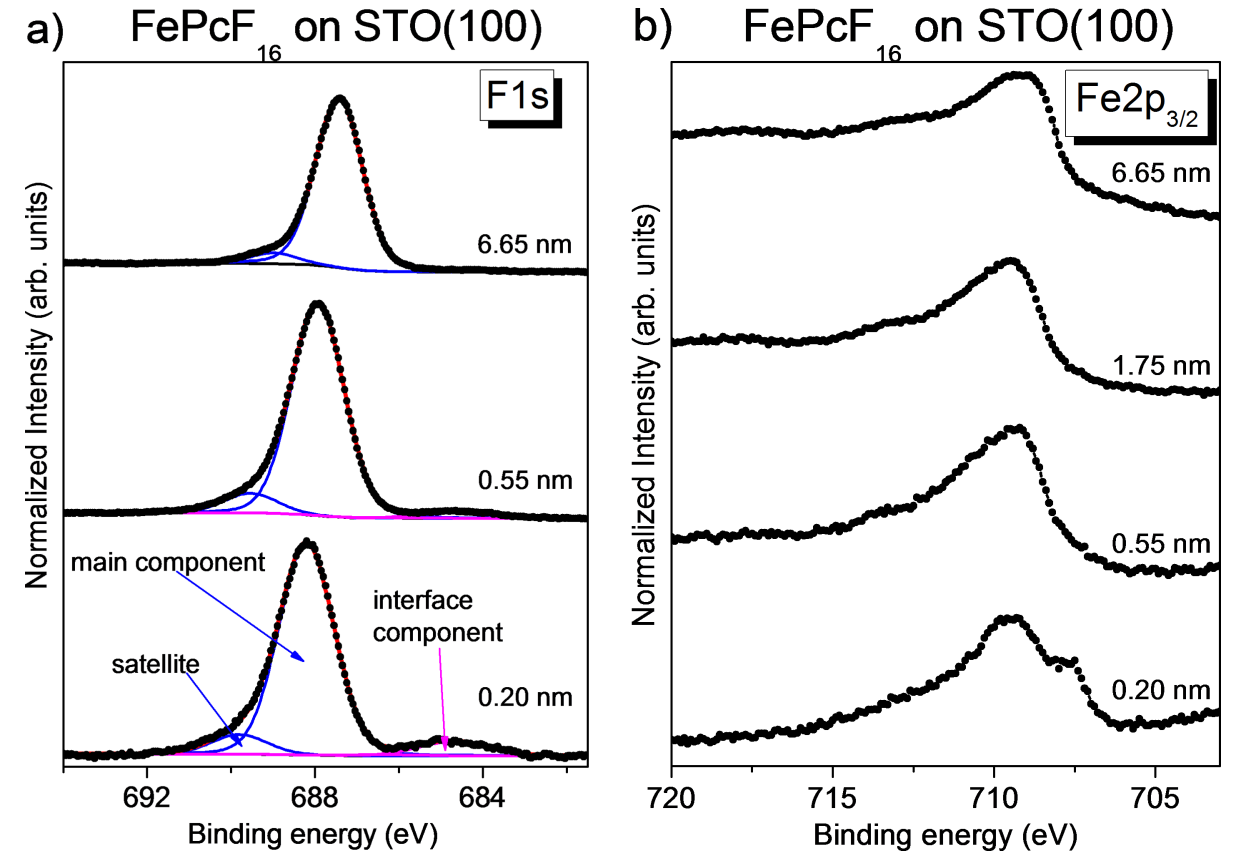

Figure 6: $\mathrm{FePcF}_{16}$ on $\mathrm{STO}(100)$. Thickness-dependent $\mathrm{F} 1 \mathrm{~s}(\mathrm{a})$ and $\mathrm{Fe} 2 \mathrm{p}_{3 / 2}$ (b) core level spectra. The interface component in the Fe $2 \mathrm{p}_{3 / 2}$ spectra (see arrow) is similar to that in the FePc spectra (Figure 5). 


\section{Influence of the STO(100) preparation on interface interactions}

We will study the influence of the substrate preparation on the interface properties at the example of CoPc. Substrates were alternatively prepared according to preparation II described in the Experimental section, where the last preparation step was the evaporation of Ti under oxygen partial pressure followed by annealing. Two experiments were performed using substrates with slightly different work functions (experiment 1: $\phi_{\mathrm{F}}=4.15 \mathrm{eV}$ and experiment 2: $\left.\phi_{\mathrm{F}}=3.93 \mathrm{eV}\right)$. Substraterelated core level spectra show (similar to preparation I) no significant changes upon $\mathrm{CoPc}$ deposition for both experiments (Figure S11 and Figure S12, Supporting Information File 1). Also, the thickness dependences of macrocycle-related $\mathrm{N} 1 \mathrm{~s}$ and C 1s core level spectra (Figure S13 and S14, Supporting Information File 1) are very similar to those of CoPc on STO(100) prepared according to preparation I.

Small differences might be visible in the intensity of the interface component in Co $2 p$ spectra for monolayer coverage of CoPc on differently prepared STO(100) surfaces (Figure 7). The complete thickness-dependent series for $\mathrm{CoPc}$ on STO(100) prepared according preparation II are given in Figure S15 (Supporting Information File 1). The spectrum of CoPc on

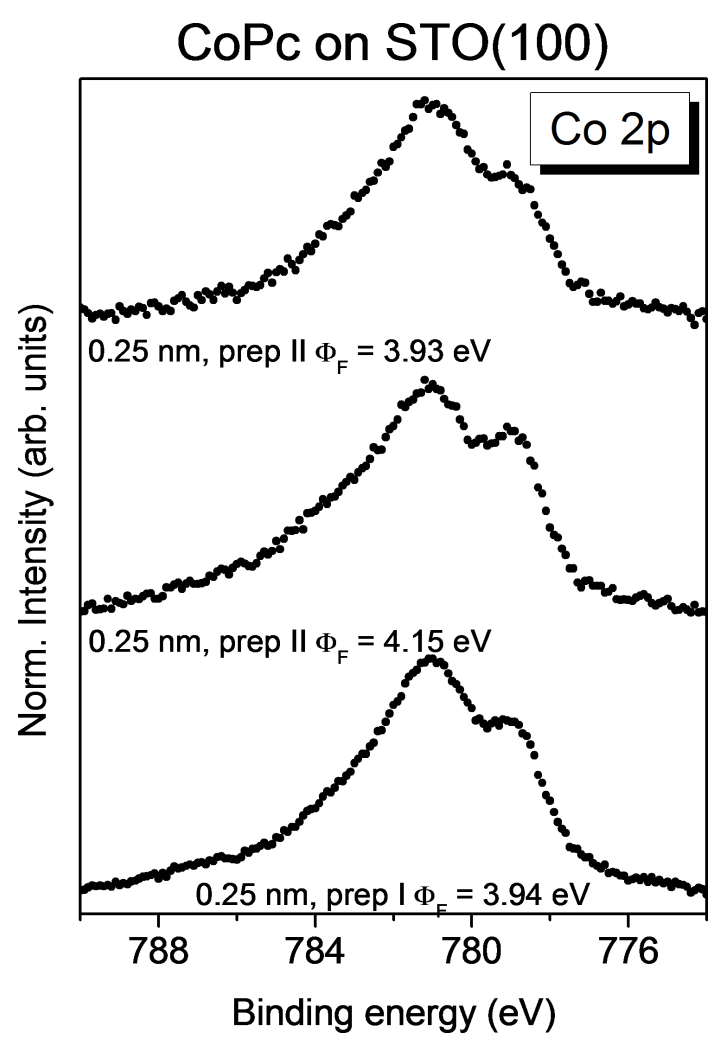

Figure 7: CoPc on $\mathrm{STO}(100)$. Co $2 \mathrm{p}_{3 / 2}$ core level spectra for a monolayer of $\mathrm{CoPc}$ deposited on differently prepared STO surfaces.
STO (preparation I) is comparable to that in Figure 3c. For better comparability, it was taken from another experiment measured using a non-monochromatized X-ray source. It seems that the relative intensity of the interface component is somewhat higher for CoPc on the STO substrate with the highest work function (Figure 7, middle) compared to the other two substrate preparations. The reason might be a different surface termination; but slightly different preparation conditions may affect also the surface morphology and roughness. Notably, for all three preparations the intensity of the interface component is in the range between $40 \%$ and $60 \%$. That is, only for about the half of the molecules an interaction between the Co ion and the $\mathrm{STO}(100)$ substrate is visible.

Thus, in our case, the preparation seems to have little influence on the interaction between CoPc and STO(100). We emphasize, however, that we obtained a mixed substrate termination for all three preparation procedures.

\section{Conclusion}

We studied interface properties of $\mathrm{CoPcF}_{x}$ and $\mathrm{FePcF}_{x}(x=0$ or 16) on niobium-doped STO(100) surfaces. For all molecules, different shifts of core level photoemission peaks with overlayer thickness were observed, indicating a charge transfer from the macrocycle to the substrate. For a distinct number of molecules of the first monolayer (30-80\%), an opposite electron transfer to the central metal atom was concluded from transition metal $2 \mathrm{p}$ spectra. Thus, the results point to a rather complex, bidirectional charge transfer involving both the macrocycle and the central metal atom of the studied molecules. In addition, for fluorinated molecules, the breaking of some (up to three per molecule) C-F bonds was observed. The number of interacting molecules depends on the central metal atom $\left(\mathrm{CoPcF}_{x}>\mathrm{FePcF}_{x}\right)$, most likely due to different adsorption geometries or a different ability to interact with less reactive adsorption sites of the substrate. Additionally, for the example of CoPc on STO(100) it was shown that the applied substrate preparation procedures have little influence on interface properties.

We emphasize, that the interaction mechanism is very different to related rutile $\mathrm{TiO}_{2}$ surfaces, where strong local interactions via the nitrogen atoms were observed $[47,50]$. In contrast, interactions via the central metal atom are hardly observed on rutile $\mathrm{TiO}_{2}$ [50]. A reason for the different behavior of rutile and STO(100) surfaces might be the different composition of the outermost surface layer. For rutile $\mathrm{TiO}_{2}$ surfaces the topmost layer consists of oxygen ions, whereas for STO(100), depending on the termination, $\mathrm{Ti}$ or $\mathrm{Sr}$ atoms are also present on the surface. The STO(100) surfaces prepared in this study exhibit a mixed surface termination. Consequently, the interface interac- 
tion between the central metal atom of a part of the $\mathrm{TMPcF}_{x}$ molecules in the first monolayer might be related to local interactions with $\mathrm{Ti}$ and/or $\mathrm{Sr}$ atoms. Also, interactions between the macrocycle of the TMPc and the rutile $\mathrm{TiO}_{2}$ surfaces seem to depend critically on the number of surface defects [50]. Thus, the absence of interface components (e.g., in $\mathrm{N}$ 1s spectra) for the TMPcs on STO(100) may point to a comparably defect-free surface. The cleavage of some intramolecular $\mathrm{C}-\mathrm{F}$ bonds of $\mathrm{TMPcF}_{16}$ was observed at both $\mathrm{STO}(100)$ and defect-rich rutile surfaces. Since not all C-F bonds are broken, this reaction occurs only at particular sites. It seems that, generally, such oxidic surfaces are more prone to support the cleavage of intramolecular $\mathrm{C}-\mathrm{F}$ bonds in comparison to metal surfaces.

\section{Supporting Information}

\section{Supporting Information File 1}

Additional experimental data.

[https://www.beilstein-journals.org/bjnano/content/

supplementary/2190-4286-12-39-S1.pdf]

\section{Acknowledgements}

The authors thank Dr. M. Turad and Patrick T. Michel for fruitful discussions, technical support, and experimental help with the substrate preparation.

\section{Funding}

This research received no external funding.

\section{ORCID ${ }^{\circledR}$ iDs}

Reimer Karstens - https://orcid.org/0000-0002-7104-3433 Heiko Peisert - https://orcid.org/0000-0002-9742-5800

\section{References}

1. Grätzel, M. J. Photochem. Photobiol., C 2003, 4, 145-153. doi:10.1016/s1389-5567(03)00026-1

2. Koch, N. ChemPhysChem 2007, 8, 1438-1455 doi:10.1002/cphc.200700177

3. Diebold, U. Surf. Sci. Rep. 2003, 48, 53-229. doi:10.1016/s0167-5729(02)00100-0

4. Karamat, S.; Ke, C.; Inkaya, U. Y.; Akram, R.; Yildiz, I.; Zaman, S. S.; Oral, A. Prog. Nat. Sci.: Mater. Int. 2016, 26, 422-426. doi:10.1016/j.pnsc.2016.06.010

5. Sato, N.; Harada, Y.; Terashima, T.; Kanda, R.; Takano, M. Appl. Surf. Sci. 2005, 244, 588-592. doi:10.1016/j.apsusc.2004.10.127

6. Yang, Y.-C.; Xu, L.; Huang, W.-Q.; Luo, C.-Y.; Huang, G.-F.; Peng, P. J. Phys. Chem. C 2015, 119, 19095-19104. doi:10.1021/acs.jpcc.5b03630

7. Yadav, S.; Ghosh, S. ACS Appl. Mater. Interfaces 2016, 8, 10436-10442. doi:10.1021/acsami.6b02847
8. Yan, H.; Jo, T.; Okuzaki, H. Jpn. J. Appl. Phys. 2010, 49, 030203. doi:10.1143/jjap.49.030203

9. Mahmoud, W. E. J. Phys. D: Appl. Phys. 2009, 42, 155502. doi:10.1088/0022-3727/42/15/155502

10. Kalappattil, V.; Geng, R.; Liang, S. H.; Mukherjee, D.; Devkota, J.; Roy, A.; Luong, M. H.; Lai, N. D.; Hornak, L. A.; Nguyen, T. D.; Zhao, W. B.; Li, X. G.; Duc, N. H.; Das, R.; Chandra, S.; Srikanth, H.; Phan, M. H. J. Sci.: Adv. Mater. Devices 2017, 2, 378-384. doi:10.1016/j.jsamd.2017.07.010

11. van Benthem, K.; Elsässer, C.; French, R. H. J. Appl. Phys. 2001, 90, 6156-6164. doi:10.1063/1.1415766

12. Kawasaki, M.; Takahashi, K.; Maeda, T.; Tsuchiya, R.; Shinohara, M.; Ishiyama, O.; Yonezawa, T.; Yoshimoto, M.; Koinuma, H. Science 1994, 266, 1540-1542. doi:10.1126/science.266.5190.1540

13. Hatch, R. C.; Choi, M.; Posadas, A. B.; Demkov, A. A. J. Vac. Sci. Technol., B: Nanotechnol. Microelectron.: Mater., Process., Meas., Phenom. 2015, 33, 061204. doi:10.1116/1.4931616

14. Connell, J. G.; Isaac, B. J.; Ekanayake, G. B.; Strachan, D. R.; Seo, S. S. A. Appl. Phys. Lett. 2012, 101, 251607. doi:10.1063/1.4773052

15. Koster, G.; Kropman, B. L.; Rijnders, G. J. H. M.; Blank, D. H. A.; Rogalla, H. Appl. Phys. Lett. 1998, 73, 2920-2922. doi:10.1063/1.122630

16. Koo, B.; Kim, K.; Kim, J. K.; Kwon, H.; Han, J. W.; Jung, W. Joule 2018, 2, 1476-1499. doi:10.1016/j.joule.2018.07.016

17. Kubo, T.; Nozoye, H. Phys. Rev. Lett. 2001, 86, 1801-1804. doi:10.1103/physrevlett.86.1801

18. Szot, K.; Speier, W.; Breuer, U.; Meyer, R.; Szade, J.; Waser, R. Surf. Sci. 2000, 460, 112-128. doi:10.1016/s0039-6028(00)00522-7

19. Chambers, S. A.; Sushko, P. V. Phys. Rev. Mater. 2019, 3, 125803. doi:10.1103/physrevmaterials.3.125803

20. Iwaya, K.; Shimizu, R.; Ohsawa, T.; Hashizume, T.; Hitosugi, T. Phys. Rev. B 2011, 83, 125117. doi:10.1103/physrevb.83.125117

21. Hikita, T.; Hanada, T.; Kudo, M.; Kawai, M. J. Vac. Sci. Technol., A 1993, 11, 2649-2654. doi:10.1116/1.578620

22. Ohnishi, T.; Shibuya, K.; Lippmaa, M.; Kobayashi, D.; Kumigashira, H.; Oshima, M.; Koinuma, H. Appl. Phys. Lett. 2004, 85, 272-274. doi:10.1063/1.1771461

23. Bachelet, R.; Sánchez, F.; Palomares, F. J.; Ocal, C.; Fontcuberta, J. Appl. Phys. Lett. 2009, 95, 141915. doi:10.1063/1.3240869

24. Fragneto, A.; De Luca, G. M.; Di Capua, R.; Scotti di Uccio, U.; Salluzzo, M.; Torrelles, X.; Lee, T.-L.; Zegenhagen, J. Appl. Phys. Lett. 2007, 91, 101910. doi:10.1063/1.2779972

25. Kobayashi, D.; Hashimoto, R.; Chikamatsu, A.; Kumigashira, H.; Oshima, M.; Ohnishi, T.; Lippmaa, M.; Ono, K.; Kawasaki, M.; Koinuma, H. J. Electron Spectrosc. Relat. Phenom. 2005, 144-147, 443-446. doi:10.1016/j.elspec.2005.01.167

26. Pancotti, A.; Barrett, N.; Zagonel, L. F.; Vanacore, G. M. J. Appl. Phys. 2009, 106, 034104. doi:10.1063/1.3183938

27. Castell, M. R. Surf. Sci. 2002, 505, 1-13. doi:10.1016/s0039-6028(02)01393-6

28. Sánchez, F.; Ocal, C.; Fontcuberta, J. Chem. Soc. Rev. 2014, 43, 2272-2285. doi:10.1039/c3cs60434a

29. Peisert, H.; Knupfer, M.; Schwieger, T.; Fuentes, G. G.; Olligs, D.; Fink, J.; Schmidt, T. J. Appl. Phys. 2003, 93, 9683-9692. doi:10.1063/1.1577223

30. Brinkmann, H.; Kelting, C.; Makarov, S.; Tsaryova, O.; Schnurpfeil, G.; Wöhrle, D.; Schlettwein, D. Phys. Status Solidi A 2008, 205, 409-420. doi:10.1002/pssa.200723391 
31. Meiss, J.; Merten, A.; Hein, M.; Schuenemann, C.; Schäfer, S.; Tietze, M.; Uhrich, C.; Pfeiffer, M.; Leo, K.; Riede, M. Adv. Funct. Mater. 2012, 22, 405-414. doi:10.1002/adfm.201101799

32. Mayer, T.; Hunger, R.; Klein, A.; Jaegermann, W. Phys. Status Solidi B 2008, 245, 1838-1848. doi:10.1002/pssb.200879542

33. Greulich, K.; Belser, A.; Bölke, S.; Grüninger, P.; Karstens, R.; Sättele, M. S.; Ovsyannikov, R.; Giangrisostomi, E.; Basova, T. V.; Klyamer, D.; Chassé, T.; Peisert, H. J. Phys. Chem. C 2020, 124, 16990-16999. doi:10.1021/acs.jpcc.0c03862

34. Schuster, B.-E.; Basova, T. V.; Plyashkevich, V. A.; Peisert, H.; Chassé, T. Thin Solid Films 2010, 518, 7161-7166. doi:10.1016/j.tsf.2010.06.030

35. Klyamer, D. D.; Sukhikh, A. S.; Krasnov, P. O.; Gromilov, S. A.; Morozova, N. B.; Basova, T. V. Appl. Surf. Sci. 2016, 372, 79-86. doi:10.1016/j.apsusc.2016.03.066

36. Sukhikh, A. S.; Klyamer, D. D.; Parkhomenko, R. G.; Krasnov, P. O.; Gromilov, S. A.; Hassan, A. K.; Basova, T. V. Dyes Pigm. 2018, 149, 348-355. doi:10.1016/j.dyepig.2017.10.024

37. de Oteyza, D. G.; El-Sayed, A.; Garcia-Lastra, J. M.; Goiri, E.; Krauss, T. N.; Turak, A.; Barrena, E.; Dosch, H.; Zegenhagen, J.; Rubio, A.; Wakayama, Y.; Ortega, J. E. J. Chem. Phys. 2010, 133, 214703. doi:10.1063/1.3509394

38. Rückerl, F.; Waas, D.; Büchner, B.; Knupfer, M. J. Electron Spectrosc. Relat. Phenom. 2017, 215, 1-7. doi:10.1016/j.elspec.2016.11.013

39. Peisert, H.; Uihlein, J.; Petraki, F.; Chassé, T. J. Electron Spectrosc. Relat. Phenom. 2015, 204, 49-60. doi:10.1016/j.elspec.2015.01.005

40. Balle, D.; Adler, H.; Grüninger, P.; Karstens, R.; Ovsyannikov, R.; Giangrisostomi, E.; Chassé, T.; Peisert, H. J. Phys. Chem. C 2017, 121, 18564-18574. doi:10.1021/acs.jpcc.7b04494

41. Yeh, J. J.; Lindau, I. At. Data Nucl. Data Tables 1985, 32, 1-155. doi:10.1016/0092-640x(85)90016-6

42. Ballirano, P.; Caminiti, R.; Ercolani, C.; Maras, A.; Orrù, M. A. J. Am. Chem. Soc. 1998, 120, 12798-12807. doi:10.1021/ja973815p

43. Evangelisti, M.; Bartolomé, J.; de Jongh, L. J.; Filoti, G. Phys. Rev. B 2002, 66, 144410. doi:10.1103/physrevb.66.144410

44. Gould, R. D. Coord. Chem. Rev. 1996, 156, 237-274. doi:10.1016/s0010-8545(96)01238-6

45. Hesse, R.; Chassé, T.; Streubel, P.; Szargan, R. Surf. Interface Anal. 2004, 36, 1373-1383. doi:10.1002/sia.1925

46. Momma, K.; Izumi, F. J. Appl. Crystallogr. 2011, 44, 1272-1276. doi:10.1107/s0021889811038970

47. Palmgren, P.; Nilson, K.; Yu, S.; Hennies, F.; Angot, T.; Layet, J.-M.; Le Lay, G.; Göthelid, M. J. Phys. Chem. C 2008, 112, 5972-5977. doi:10.1021/jp711311s

48. Sinha, S.; Islam, A. K. M. M.; Vorokhta, M.; Mukherjee, M. J. Phys. Chem. C 2017, 121, 3365-3372. doi:10.1021/acs.jpcc.6b10803

49. Ishida, N.; Fujita, D. J. Phys. Chem. C 2012, 116, 20300-20305. doi:10.1021/jp303152c

50. Karstens, R.; Glaser, M.; Belser, A.; Balle, D.; Polek, M.; Ovsyannikov, R.; Giangrisostomi, E.; Chassé, T.; Peisert, H. Molecules 2019, 24, 4579. doi:10.3390/molecules24244579

51. Raisch, C.; Chassé, T.; Langheinrich, C.; Chassé, A. J. Appl. Phys. 2012, 112, 073505. doi:10.1063/1.4757283

52. Chassé, A.; Chassé, T. J. Phys. Soc. Jpn. 2018, 87, 061006. doi:10.7566/jpsj.87.061006
53. Brena, B.; Luo, Y.; Nyberg, M.; Carniato, S.; Nilson, K.; Alfredsson, Y.; Åhlund, J.; Mårtensson, N.; Siegbahn, H.; Puglia, C. Phys. Rev. B 2004, 70, 195214. doi:10.1103/physrevb.70.195214

54. Peisert, H.; Knupfer, M.; Fink, J. Synth. Met. 2003, 137, 869-870. doi:10.1016/s0379-6779(02)01095-0

55. Petraki, F.; Peisert, H.; Biswas, I.; Chassé, T. J. Phys. Chem. C 2010, 114, 17638-17643. doi:10.1021/jp104141s

56. Åhlund, J.; Nilson, K.; Schiessling, J.; Kjeldgaard, L.; Berner, S.; Mårtensson, N.; Puglia, C.; Brena, B.; Nyberg, M.; Luo, Y. J. Chem. Phys. 2006, 125, 034709. doi:10.1063/1.2212404

57. Lukasczyk, T.; Flechtner, K.; Merte, L. R.; Jux, N.; Maier, F.; Gottfried, J. M.; Steinrück, H.-P. J. Phys. Chem. C 2007, 111, 3090-3098. doi:10.1021/jp0652345

58. Schmid, M.; Kaftan, A.; Steinrück, H.-P.; Gottfried, J. M. Surf. Sci. 2012, 606, 945-949. doi:10.1016/j.susc.2012.02.012

59. Wang, J. Y.; Wang, J. Y.; Dougherty, D. B. J. Vac. Sci. Technol., B: Nanotechnol. Microelectron.: Mater., Process., Meas., Phenom. 2020, 38, 053401. doi:10.1116/6.0000401

60. Glaser, M.; Peisert, H.; Adler, H.; Aygül, U.; Ivanovic, M.; Nagel, P.; Merz, M.; Schuppler, S.; Chassé, T. J. Chem. Phys. 2015, 142, 101918. doi:10.1063/1.4907899

61. Toader, M.; Shukrynau, P.; Knupfer, M.; Zahn, D. R. T.; Hietschold, M. Langmuir 2012, 28, 13325-13330. doi:10.1021/la302792z

62. Petraki, F.; Peisert, H.; Uihlein, J.; Aygül, U.; Chassé, T. Beilstein J. Nanotechnol. 2014, 5, 524-531. doi:10.3762/bjnano.5.61

63. Yu, J. C.; Yu, J. G.; Ho, W. K.; Jiang, Z. T.; Zhang, L. Z. Chem. Mater. 2002, 14, 3808-3816. doi:10.1021/cm020027c

64. Yu, J.; Xiang, Q.; Ran, J.; Mann, S. CrystEngComm 2010, 12, 872-879. doi:10.1039/b914385h

65. Schmidt, C.; Breuer, T.; Wippermann, S.; Schmidt, W. G.; Witte, G. J. Phys. Chem. C 2012, 116, 24098-24106. doi:10.1021/jp307316r

66. Petraki, F.; Peisert, H.; Aygül, U.; Latteyer, F.; Uihlein, J.; Vollmer, A.; Chassé, T. J. Phys. Chem. C 2012, 116, 11110-11116. doi:10.1021/jp302233e

67. Glaser, M.; Peisert, H.; Adler, H.; Polek, M.; Uihlein, J.; Nagel, P.; Merz, M.; Schuppler, S.; Chassé, T. J. Phys. Chem. C 2015, 119, 27569-27579. doi:10.1021/acs.jpcc.5b09612

68. Rauls, E.; Schmidt, W. G.; Pertram, T.; Wandelt, K. Surf. Sci. 2012, 606, 1120-1125. doi:10.1016/j.susc.2012.03.010

69. Belser, A.; Karstens, R.; Grüninger, P.; Nagel, P.; Merz, M.; Schuppler, S.; Suturina, E. A.; Chassé, A.; Chassé, T.; Peisert, H. J. Phys. Chem. C 2018, 122, 15390-15394. doi:10.1021/acs.jpcc.8b03436 


\section{License and Terms}

This is an Open Access article under the terms of the Creative Commons Attribution License (https://creativecommons.org/licenses/by/4.0). Please note that the reuse, redistribution and reproduction in particular requires that the author(s) and source are credited and that individual graphics may be subject to special legal provisions.

The license is subject to the Beilstein Journal of Nanotechnology terms and conditions: (https://www.beilstein-journals.org/bjnano/terms)

The definitive version of this article is the electronic one which can be found at:

https://doi.org/10.3762/bjnano.12.39 